\title{
Diagnostic accuracy of methacholine challenge tests assessing airway hyperreactivity in asthmatic patients - a multifunctional approach
}

\author{
Richard Kraemer ${ }^{1 *}$ (D) Hans-Jürgen Smith², Thomas Sigrist ${ }^{3}$, Gabi Giger $^{3}$, Roland Keller ${ }^{3}$ and Martin Frey ${ }^{3}$
}

\begin{abstract}
Background: There are few studies comparing diagnostic accuracy of different lung function parameters evaluating dose-response characteristics of methacholine $(\mathrm{MCH})$ challenge tests $(\mathrm{MCT})$ as quantitative outcome of airway hyperreactivity (AHR) in asthmatic patients. The aim of this retrospectively analysis of our database (Clinic Barmelweid, Switzerland) was, to assess diagnostic accuracy of several lung function parameters quantitating AHR by dose-response characteristics.
\end{abstract}

Methods: Changes in effective specific airway conductance $\left(\mathrm{sG}_{\mathrm{eff}}\right)$ as estimate of the degree of bronchial obstruction were compared with concomitantly measured forced expiratory volume in $1 \mathrm{~s}\left(\mathrm{FEV}_{1}\right)$ and forced expiratory flows at $50 \%$ forced vital capacity $\left(\mathrm{FEF}_{50}\right)$. According to the GINA Guidelines the patients $(n=484)$ were classified into asthmatic patients $(n=337)$ and non-asthmatic subjects $(n=147)$. Whole-body plethysmography (CareFusion, Würzburg, Germany) was performed using ATS-ERS criteria, and for the MCTs a standardised computer controlled protocol with 3 consecutive cumulative provocation doses $\left(\mathrm{PD}_{1}: 0.2 \mathrm{mg} ; \mathrm{PD}_{2}: 1.0 \mathrm{mg} ; \mathrm{PD}_{3}: 2.2 \mathrm{mg}\right.$ ) was used. Break off criterion for the MCTs were when a decrease in $\mathrm{FEV}_{1}$ of $20 \%$ was reached or respiratory symptoms occurred.

Results: In the assessment of AHR, whole-body plethysmography offers in addition to spirometry indices of airways conductance and thoracic lung volumes, which are incorporated in the parameter $s \mathrm{G}_{\text {eff, }}$ derived from spontaneous tidal breathing. The cumulative percent dose-responses at each provocation step were at the $1^{\text {st }}$ level step $(0.2 \mathrm{mg}$ MCH) 3.7 times, at the $2^{\text {nd }}$ level step $(1 \mathrm{mg} \mathrm{MCH}) 2.4$ times, and at the $3^{\text {rd }}$ level step $(2.2 \mathrm{mg} \mathrm{MCH}) 2.0$ times more pronounced for $\mathrm{sG}_{\text {eff }}$, compared to $\mathrm{FEV}_{1}$. A much better diagnostic odds ratio of $\mathrm{sG}_{\text {eff }}(7.855)$ over $\mathrm{FEV}_{1}(6.893)$ and $\mathrm{FEF}_{50}$ (4.001) could be found. Moreover, the so-called dysanapsis, and changes of end-expiratory lung volume were found to be important determinants of AHR.

Conclusions: Applying plethysmographic tidal breathing analysis in addition to spirometry in MCTs provides relevant advantages. The absence of deep and maximal inhalations and forced expiratory manoeuvres improve the subject's cooperation and coordination, and provide sensitive and differentiated test results, improving diagnostic accuracy. Moreover, by the combined assessment, pulmonary hyperinflation and dysanapsis can be respected in the differentiation between "asthmatics" and "non-asthmatics".

Keywords: (1) Airway hyperreactivity, (2) Bronchial asthma, (3) Methacholine challenge test, (4) Whole-body plethysmography, (5) Effective, specific airway conductance, (6) Diagnostic accuracy, (7) Dysanapsis

\footnotetext{
*Correspondence: richard.kraemer@swissonline.ch

${ }^{1}$ Department of Clinical Research, University of Berne, Kirchenfeldstrasse 74,

$\mathrm{CH}-3005$ Berne, Switzerland

Full list of author information is available at the end of the article
} 


\section{Background}

Airway hyperreactivity (AHR) is a characteristic feature of bronchial asthma, and methacholine challenge testing (MCT) is well established to quantitate AHR in patients with unexplained symptoms such as cough, chest tightness and/or dyspnea, when the diagnosis of asthma is uncertain [1-10]. Compared to control subjects the provoked bronchial obstruction appears earlier and at lower provocation doses, and is more intensive in patients with asthma, a functional feature serving as rationale for the underlying mechanisms of AHR $[4,11,12]$. Both the European Respiratory Society (ERS) [1] and the American Thoracic Society (ATS) [4] recommend bronchial provocation tests by inhalation of aerosolized methacholine $(\mathrm{MCH})$, considering this approach to be a reproducible and relatively easy to perform test in adults and children.

Following MCT, the cumulative provocation dose (PD) at which the forced expiratory volume in $1 \mathrm{~s}\left(\mathrm{FEV}_{1}\right)$, measured with spirometry, decreases at least $20 \%$ compared to baseline $\left(\mathrm{PD}_{-20} \mathrm{FEV}_{1}\right)$, is currently the most commonly used outcome of assessing AHR by detection of flow limitation in consequence of airway narrowing [9]. Alternatively, whole-body plethysmography can also be used to determine AHR, measuring changes in airway mechanics either by a $35 \%[2,7]$, a $40 \%[4,5]$, or a $50 \%$ [5] reduction in specific airway conductance $\left(\mathrm{sG}_{\mathrm{aw}}\right)$ or an increase of specific airway resistance $\left(\mathrm{sR}_{\mathrm{aw}}\right)$ of $100 \%$ $[8,10]$ from baseline. To our knowledge, studies comparing reliability of spirometric parameters with those obtained by whole-body plethysmography, or even a combination of both are rare, and the so-called effective specific airway conductance $\left(\mathrm{sG}_{\text {eff }}\right)$ has never been evaluated as a target parameter.

Therefore, the purpose of the present study was to compare diagnostic value of the response characteristics to $\mathrm{MCH}$ assessed by $\mathrm{FEV}_{1}$ and forced expiratory flow at $50 \%$ of vital capacity $\left(\mathrm{FEF}_{50}\right)$, in relation to $s \mathrm{G}_{\text {eff }}$ differentiating different diagnostic and functional groups and to encounter possible differences of AHR in relation to pulmonary hyperinflation and/or the phenomenon of dysanapsis [13-17].

\section{Methods}

\section{Study population and ethics}

The study was conducted in the Division of Pulmonary Medicine, Clinic Barmelweid, CH-5017 Barmelweid, Switzerland, recruiting patients referred to the pulmonary function laboratory for baseline pulmonary function and MCT in patients with symptoms suggestive for asthma, such as cough, shortness of breath, wheezing or chest tightness. According to the classical definition of the GINA dissemination committee report [18], and based on the characteristics of the case histories and clinical findings, two experienced pulmonary physicians (Co-authors MF and TS) have classified the cases previously into a group of patients with proven bronchial asthma $(n=337 ; 69.8 \%)$, and a group of non-asthmatic subjects $(n=147 ; 30.4 \%)$. Bronchial asthma was diagnosed when subjects presented with a medical history of atopy (allergic rhinitis, hay fever, exercise-induced, partly also an eosinophilic inflammation, infection-induced, occupational or intrinsic), and documented with a positive MCT ( $\left.\mathrm{PD}_{-20} \mathrm{FEV}_{1}\right)$. The groups of non-asthmatic subjects was composed of 4 subgroups according to the potential origin of pulmonary symptoms differentiating either between $(i)$ an "upper airway syndrome" (UACS), previously also termed as post-nasal-drip-syndrome [19] ( $n=55 ; 37.4 \%),(i i)$ a gastroesophageal reflux disease (GERD, $n=40 ; 27.2 \%$ ), (iii) "persistent chronic cough" lasting more than 8 weeks [20] $(n=30 ; 20.4 \%)$, and patients with (iv) a "symptom complex" such as unexplained dyspnoea, chest tightness, hyperventilation, or somatisation $(n=22 ; 15.0 \%)$, which could not be attributed to a clear diagnosis. There were no patients with chronic obstructive pulmonary disease (COPD), bronchiectasis, cystic fibrosis, obstructive sleep apnoea syndrome (OSAS), or interstitial lung disease. Short-acting $\beta_{2}$-agonists were withdrawn for $8 \mathrm{~h}$, long-acting betaagonists for $48 \mathrm{~h}$, and leukotriene receptor antagonists for $24 \mathrm{~h}$ prior to the lung function testing. Inhaled corticosteroids were withdrawn 7 days before MCT.

We conducted this study retrospectively as a case controlled study in order to compare diagnostic accuracy of the MCT assessed by different target parameters between the diagnosed asthmatic patients and non-asthmatic subjects. Inclusion criteria were reproducible base-line measurements, at least 5 plethysmographic tidal breath efforts as well as at least 3 reproducible forced expiratory manoeuvres at each provocation level. The study was planned according to the Federal Law of Human Research, conceptualized according to the Swiss Ethics Committee on Research involving humans, and approved by the Governmental Ethics Committee of the State of Berne. Master-files haven been stored and secured in the REDCap-system of the Clinical Trial Unit, Medical Faculty, University of Berne, Switzerland.

\section{Pulmonary function procedures}

Spirometry and plethysmographic measurements were performed using standard techniques according to ATSERS recommendations [21, 22] previously established and subsequently extended (http://www.atsjournals.org/doi/ suppl/10.1164/rccm.200407-948OC/suppl_file/online_ methods.pdf) [23]; http://www.atsjournals.org/doi/suppl/ 10.1164/rccm.200603-423OC/suppl_file/onlinesup200603423ocr2.pdf) [24]; http://www.biomedcentral.com/content/ supplementary/1465- 9921-10-106-S1.doc) [25]. 
Using a Jaeger MasterLab whole-body plethysmograph (CareFusion, Würzburg, Germany), measurements of airway mechanics, slow spirometry and hence assessment of static lung volumes were carried out first and only afterwards forced flow-volume loops were performed according to the ATS-ERS recommendations (best value of the 3 trials). The $s R_{\text {eff, }}$ and its reciprocal value the $\mathrm{sG}_{\text {eff }}$ resp., were assessed while the subject breathed tidally, in an upright position, through filter and measuring head in the body plethysmograph [26], without requiring any special breathing manoeuvres or efforts against a closed shutter. Both measurement techniques (whole-body plethysmography and spirometry) were performed with the subjects in sitting position within the whole-body plethysmograph cabin.

\section{Assessment of airway mechanics}

In order to obtain a parallel synoptical presentation of the MCT, we routinely present the reaction of $\mathrm{FEV}_{1}$ and $\mathrm{FEF}_{50}$ together with $\mathrm{sG}$ eff. $\mathrm{sG}_{\text {eff }}$ is computed as the ratio between the integral of the area of the tidal flow-volume loop as numerator $\left(\oint V^{\prime} d V_{T}\right)$ and the integral of the area enclosed by the specific resistive work of breathing $\left(\mathrm{sWOB}=\oint \Delta V_{b o x} d V_{T}\right)[27]$ according the equation:

$$
s G_{e f f}=\frac{1}{P_{a m b}-P_{H_{2} O}} * \frac{\oint V^{\prime} d V_{T}}{\oint \Delta V_{b o x} d V_{T}}=\frac{1}{s R_{e f f}}
$$

where $\mathrm{P}_{\mathrm{amb}}$ is the barometric pressure, $\mathrm{P}_{\mathrm{H} 2 \mathrm{O}}$ the saturated vapour water pressure at body temperature. The mathematical background to obtain $\mathrm{sG}_{\text {eff }}$ as the reciprocal value of the effective specific resistance $\left(\mathrm{sR}_{\mathrm{eff}}\right)$, has been given previously [23-25, 28], and is presented synoptically in Fig. 1. An Additional file 1 furthermore provides details regarding the paradigm shift in the assessment of airway mechanics. During quiet breathing at end-expiratory lung volume (EELV) measurements of $s G_{\text {eff }}$ were measured in a first phase of testing. In a second phase of testing functional residual capacity $\left(\mathrm{FRC}_{\text {pleth }}\right)$ was assessed by normal resting breathing against the closed shutter (no panting). In a third phase a slow maximal vital capacity manoeuvre, carefully linked with the shutter-measurement was performed to get the static lung volumes, functional residual capacity $\left(\mathrm{FRC}_{\text {pleth }}\right)$, residual volume (RV) and total lung capacity (TLC). However, only in a forth phase of testing 3 consecutive forced flow-volume-loops were recorded. The median of at least 5 consecutive single measurements of $\mathrm{sG}_{\text {eff }}$ and 3 measurements of $\mathrm{FRC}_{\text {pleth }}$ were computed, and from the triplet of forced expiratory manoeuvres the best effort was analysed. The pulmonary function test data were expressed as a percentage of predicted normal values, and z-transformed accordingly [21, 29, 30].
The assessment of the dose-response characteristics to $\mathrm{MCH}$, observed not only by forced spirometry, but additionally by whole-body plethysmography, was chosen because a certain paradigm shift at least in the technical approach of the assessment of airway mechanics is established since several years, albeit the combined assessment of AHR by $\mathrm{MCH}$ by spirometry and wholebody plethysmography is not yet well validated and established in its clinical use. However, improved reliability of test results can be expected by assessing the bronchial reaction to $s G_{\text {eff }}$, which is computed real-time by an integral, multi-dimensional approach. Details are given in the Additional file 1. Our anticipated advantages, therefore, were to elaborate, whether or not in comparison to the spirometric approach, the new plethysmographic technology could provide $(i)$ better diagnostic accuracy, (ii) leading by independency of deep inspirations and hence changes in the volume-history $[10,31-36]$ to less "a priori" modulation of the airway calibre, moreover, (iii) by independency from the subject's cooperation (need of forced breathing manoeuvres) circumvention of inadvertent change of the airway responsiveness during test procedure [34, 37, 38].

\section{The aerosol provocation system (APS)}

MCT was performed according to a protocol routinely used in several pulmonary function laboratories in Europe, applying a modified dose oriented, single concentration sequence [39] with the Aerosol Provocation System (APS) using the SideStream nebulizer of Philips/ Respironics previously described [38, 40]. Technical details and advantages of the APS are given in the Additional file 2, presenting the similar physical characteristics likewise they were recently outlined by Kannan et al. [41]. In their novel efforts they defined high fidelity computational simulations, performed over several breathing cycles, to get information regarding regional deposition for different particle sizes and an algorithm accounting for the re-entry of particles during the exhalation phase.

\section{Methacholine challenge test (MCT)}

After baseline measurements, $\mathrm{MCH}$ (5\%) was administered in 3 steps of increasing dose. However, in contrast to a previously proposed 4-step procedure [39], a oneconcentration-3-step protocol with increasing single doses of $\mathrm{MCH}(0.2 \mathrm{mg}, 0.8 \mathrm{mg}, 1.2 \mathrm{mg})$ was performed, consisting of 3 consecutive levels of cumulative doses defined as $\mathrm{CD}_{1}: 0.2 \mathrm{mg} ; \mathrm{CD}_{2}: 1.0 \mathrm{mg} ; \mathrm{CD}_{3}: 2.2 \mathrm{mg}$. The measurements of whole-body plethysmography and spirometry were performed two minutes after each $\mathrm{MCH}$ inhalation. On the basis of the inhalation time and the nebulizer output provided by the APS and the known concentration of the $\mathrm{MCH}$, the applied doses of $\mathrm{MCH}$ was individually computed at each provocation level. 


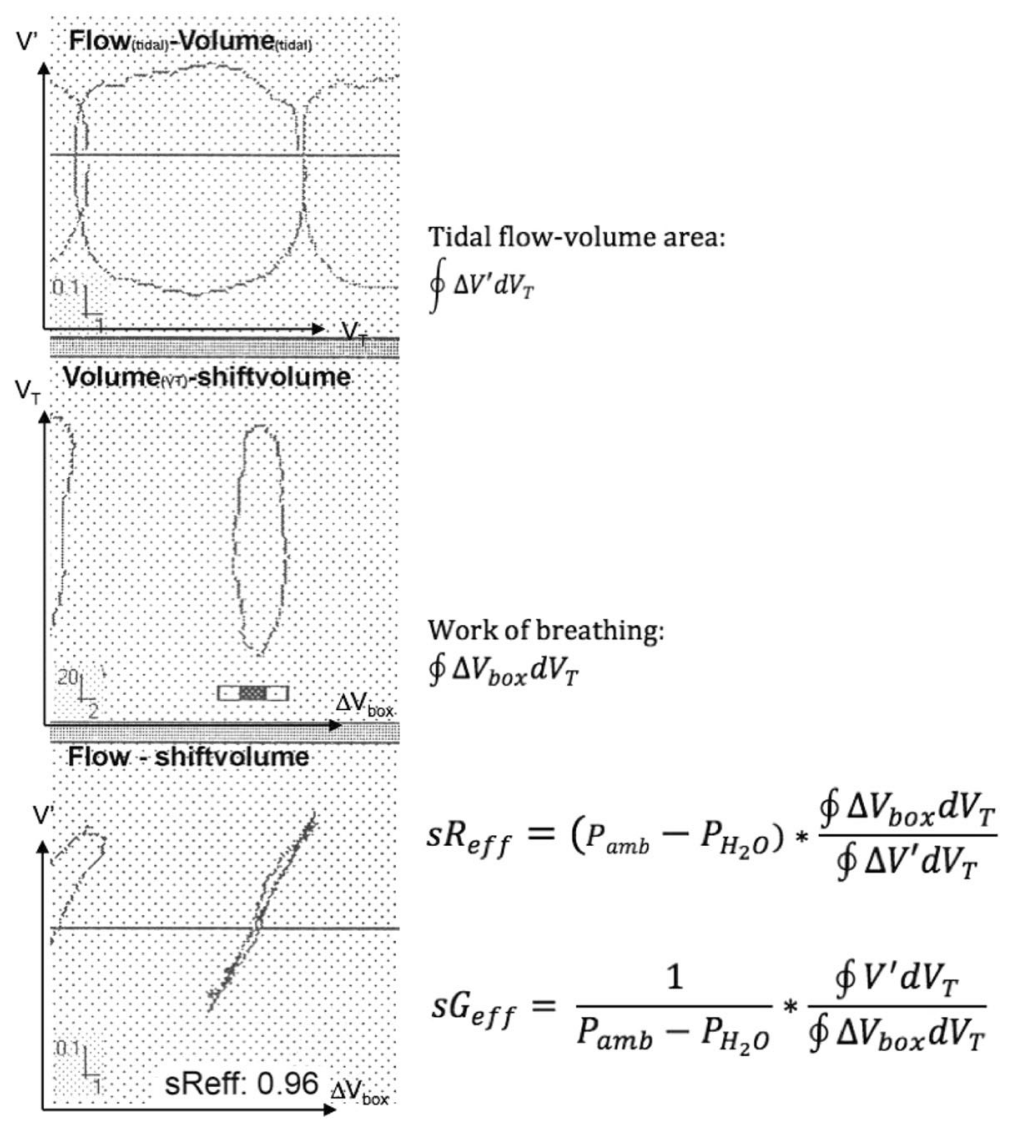

Fig. 1 Print-screen, originally depicted from the Jaeger infant whole-body plethysmograph showing breath-by-breath tracings from which effective specific resistance ( $s R_{\text {eff }}$ ), and its reciprocal value, the effective, specific airway conductance ( $\mathrm{s}_{\text {eff }}$ ) are computed using the integral of the tidal flow-volume area (upper tracing) and the integral of the plethysmographic shift-volume versus tidal volume area, the latter representing the specific resistive work of breathing (middle tracing). The crossbar clearly demonstrates that the zero-flow points are perfectly in phase

Response to $\mathrm{MCH}$ was assessed by linear regression against the logarithmic doses of $\mathrm{MCH}$ giving the individual $\mathrm{PD}$ causing either a $20 \%$ decrease of $\mathrm{FEV}_{1}\left(\mathrm{PD}_{-20} \mathrm{FEV}_{1}\right)$, a $40 \%, 45 \%$ or $50 \%$ decrease of $\mathrm{sG}_{\text {eff }}\left(\mathrm{PD}_{-40} \mathrm{~s} \mathrm{G}_{\mathrm{eff}}, \mathrm{PD}_{-45} \mathrm{sG}_{\mathrm{eff}}\right.$, $\mathrm{PD}_{-50} \mathrm{SG}_{\mathrm{eff}}$, resp.), or a $20 \%$ decrease of $\mathrm{FEF}_{50}\left(\mathrm{PD}_{-20} \mathrm{FEF}_{50}\right)$. A synopsis of the assessment of AHR by this technique is presented in the Additional file 3. Break off criterion were when a decrease in $\mathrm{FEV}_{1}>20 \%$ was reached or symptoms occurred. After having defined $\mathrm{PD}_{-40} \mathrm{~S} \mathrm{G}_{\text {eff }}$ as the most discriminating factor and in order to distinguish the degree of AHR to $\mathrm{MCH}$, patients were classified into 4 functional severity groups: (1) non-reactive if $\mathrm{PD}_{-40} \mathrm{SG}_{\mathrm{eff}} \geq 2.0 \mathrm{mg}$, (2) low-reactive if $\mathrm{PD}_{-40} \mathrm{SG}_{\text {eff }} \geq 1.0 \mathrm{mg}$ but $<2.0 \mathrm{mg}$, (3) medium-reactive if $\mathrm{PD}_{-40} \mathrm{SG}_{\text {eff }} \geq 0.2 \mathrm{mg}$ but $<1.0 \mathrm{mg}$, or (4) severe $A H R$, if $P_{-40} S G_{\text {eff }}<0.2 \mathrm{mg}$. Each provocation test was terminated with 2 puffs of salbutamol inhaled from spacer device.

\section{Data analysis and statistical methods}

The discriminative power of each lung function parameter was evaluated by measures of diagnostic accuracy such as sensitivity, specificity, positive predictive values (PPV), negative predicting values (NPV), likelihood ratios (LR+; LR-), the area under receiver operating curves (ROC), the Youden's index (J) and diagnostic odds ratios (DOR). Statistical comparisons were performed applying McNemar testing. Using these different statistical procedures several aspects of diagnostic accuracy, such as predictive ability and/or discriminative property of the MCT, could be evaluated [42]. The Additional file 4 (Statistical Approach) provides details of all the statistic methods applied. Diagnostic accuracy was tested in a first step by cross-tabulation comparing the proportions of positive and negative reaction to the $\mathrm{MCH}$ challenge for each parameter $\left(\mathrm{sG}_{\mathrm{eff}}, \mathrm{FEV}_{1}\right.$ and $\mathrm{FEF}_{50}$ ) using Chi-squared tests. Statistical analysis was performed with the IBM SPSS version 24.0 (SPSS Inc., Chicago, IL). The limit of significance was a $p$-value of 0.05 .

\section{Results}

Patient characteristics

A total of 484 patients (199 males, 51.1\%; 285 females, 58.9\%; age-range 9.11-87.1 years) were eligible for 
inclusion in the study stratifying patients into a group of asthmatic patients $(n=337 ; 69.6 \%)$ and non-asthmatic subjects $(n=147 ; 30.4 \%)$ previously diagnosed. Table 1 shows that in the gender distribution, more females than males were found, especially in the group of asthmatics. Non-asthmatic subjects were slightly older than asthmatics. The distribution within age-classes (not shown) revealed that the younger the collective, the more asthmatics, and the older the collective, the more nonasthmatic subjects were found. The stratification into different functional groups assessed at baseline prior to MCT shows for plethysmographic measurements normal lung function in $83.1 \%$ of asthmatic patients and $80.3 \%$ of non-asthmatic subjects. Interestingly, a considerable percentage of patients presented with a pulmonary hyperinflation $\left(\mathrm{FRC}_{\text {pleth }}>+1.645 \mathrm{SD}\right)$, without or in combination with bronchial obstruction $\left(\mathrm{sG}_{\mathrm{eff}}<-1.645 \mathrm{SD}\right)$. Regarding spirometry, normal flow-volume curve indices were found in $90.5 \%$ of asthmatic patients and $93.9 \%$ of non-asthmatic subjects. Only a very minor percentage of asthmatic patients (7.7\%) presented with flow limitation $\left(\mathrm{FEV}_{1}<-1.645 \mathrm{SD}\right)$ at baseline.

\section{Dose-response curves obtained by using different lung function parameters}

In Fig. 2 the dose-responses to $\mathrm{MCH}$ at each provocation level, expressed as percent changes from baseline (BL set to zero) for each lung function parameter are synoptically presented, comparing response in asthmatic patients with non-asthmatic subjects. It can be shown that the response assessed by $\mathrm{sG}_{\text {eff }}$ was much quicker and much more pronounced than the response assessed by $\mathrm{FEV}_{1}$ or $\mathrm{FEF}_{50}$. The cumulative percent-responses at each cumulative dose- (CD)-level demonstrate completely different response characteristics regarding the 3 target parameters. In asthmatic patients the cumulative percent-response of $\mathrm{sG}_{\text {eff }}$ was at the $1^{\text {st }}$ PD-level $(0.2 \mathrm{mg}$ $\mathrm{MCH}) 3.7$ times more pronounced than with $\mathrm{FEV}_{1}, 1.6$ times than with $\mathrm{FEF}_{50}$ resp. At the $2^{\text {nd }} \mathrm{CD}$-level $(1 \mathrm{mg}$ $\mathrm{MCH})$ the percent-response of $\mathrm{sG}_{\text {eff }}$ was 2.4 times more pronounced than with $\mathrm{FEV}_{1}, 1.4$ times more than with $\mathrm{FEF}_{50}$ resp., and at the $3^{\text {rd }} \mathrm{CD}$-level $(2.2 \mathrm{mg} \mathrm{MCH})$ the percent-response of $\mathrm{sG}_{\text {eff }}$ was 2.0 times more pronounced than with $\mathrm{FEV}_{1}, 1.3$ times more than with $\mathrm{FEF}_{50}$ resp. By nature the percent-response in nonasthmatic subjects was 1.5 to 2.9 times lower than in asthmatic patients, but the differences in percentresponses between the lung function parameters were even more pronounced.

\section{Diagnostic accuracy of assessing AHR by using different lung function parameters}

All indices contributing to the assessment of diagnostic accuracy (Additional file 4: Statistical Approach) are summarized in Table 2, differentiating between asthmatic patients and non-asthmatic subjects. Since the cut-off level for $s G_{\text {eff }}$ is not yet clearly defined, we first compared the 3 potentially valuable thresholds

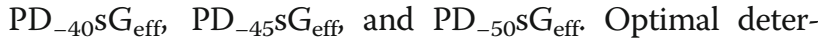
mination as represented by the highest sensitivity, highest negative predictive values, highest diagnostic odds ratios (DOR) [43], lowest negative likelihood ratios, and highest diagnostic effectiveness was found for $\mathrm{PD}_{-40} \mathrm{SG}$ eff, indicating that $\mathrm{PD}_{-40} \mathrm{~S} \mathrm{G}_{\text {eff }}$ is the most appropriate threshold for evaluating $\mathrm{AHR}$ by $\mathrm{sG}_{\text {eff }}$. Whereas the $\mathrm{PD}_{-40} \mathrm{~s} \mathrm{G}_{\text {eff }}$ level was reached in all subjects by $s G_{\text {eff }}$, the $\mathrm{PD}_{-20} \mathrm{FEV}_{1}$ was not reached by $\mathrm{FEV}_{1}$ in $9.1 \%$ of subjects and in $6.4 \%$ $\mathrm{PD}_{-20} \mathrm{FEF}_{50}$ by $\mathrm{FEF}_{50}$ respectively. Therefore, $\mathrm{PD}_{-40} \mathrm{SG}_{\text {eff }}$ measures AHR in comparison with $\mathrm{PD}_{-20} \mathrm{FEV}_{1}$ and $\mathrm{PD}_{-20} \mathrm{FEF}_{50}$ with better properties of diagnostic accuracy.

\section{Test-duration and $\mathrm{MCH}-$ doses to achieve PD-levels}

We found it of clinical relevance to compare the test duration and $\mathrm{MCH}$-doses to achieve PD-levels by the different target lung function parameters. Table 3 shows that the test duration was significantly shorter for $\mathrm{PD}_{-40} \mathrm{SG}_{\text {eff }}$ compared to $\mathrm{PD}_{-20} \mathrm{FEV}_{1}$, or $\mathrm{PD}_{-20} \mathrm{FEF}_{50}(14: 45 \pm 5: 54 \mathrm{~min}$. versus 17:46 \pm 5:16 $\mathrm{min} ; 16: 17 \pm 5: 36 \mathrm{~min}$ respectively). Consequently, the provocation doses to which subjects are exposed to $\mathrm{MCH}$ were significantly lower for $\mathrm{PD}_{-40} \mathrm{SG}_{\text {eff }}$ compared to $\mathrm{PD}_{-20} \mathrm{FEV}_{1}$, or $\mathrm{PD}_{-20} \mathrm{FEF}_{50}(0.495 \pm 0.491 \mathrm{mg}$ versus $0.739 \pm 0.615 \mathrm{mg} ; 0.625 \pm 0.588$, respectively).

\section{Influence of pulmonary hyperinflation prior to or during MCT}

Changes of end-expiratory lung volume (EELV) during MCT cannot be assessed by spirometry, especially not a shift of the flow-volume curve towards total lung capacity in consequence of dynamic hyperinflation, which results in an elevated residual volume and a decrease of inspiratory capacity and vital capacity as well. However, a shift of EELV toward total lung capacity may have an influence on the magnitude of $\mathrm{FEV}_{1}$. In 63 of 337 asthmatic patients $(18.7 \%)$ pulmonary hyperinflation was observed prior to testing, or was developed during MCT. In Fig. 3 response to $\mathrm{MCH}$ is compared in all subjects differentiating those with pulmonary hyperinflation which those without pulmonary hyperinflation. There was a much more pronounced AHR in patients with pulmonary hyperinflation (mean diff in $\mathrm{PD}_{-40} \mathrm{SG}_{\mathrm{eff}}$ : $7.5 \%$, n.s.; PD $_{-20} \mathrm{FEV}_{1}$ : $5.8 \% \quad p<0.001 ; \mathrm{PD}_{-20} \mathrm{FEF}_{50}$ : $7.6 \%$, n.s.). Noteworthy to realise that pulmonary hyperinflation influenced AHR measured by $\mathrm{PD}_{-20} \mathrm{FEV}_{1}$ significantly. Moreover interestingly, differences were not significant for $\mathrm{PD}_{-40} \mathrm{SG}$ eff. This may be a formal proof, that the assessment of AHR using the integral method of $\mathrm{sG}_{\mathrm{eff}}$, 
Table 1 Subject's characteristics ( $N=484 ; 199$ males (41.1\%, 285 females (58.9\%), age-range (9.1-87.1 years

\begin{tabular}{|c|c|c|c|c|c|c|}
\hline & \multirow[t]{2}{*}{$\begin{array}{l}\text { Asthmatic patients } \\
n=337\end{array}$} & \multicolumn{5}{|l|}{$\begin{array}{l}\text { Non-asthmatic subjects } \\
n=147\end{array}$} \\
\hline & & $\begin{array}{l}\text { Upper airway Cough } \\
\text { syndrome (UACS) }\end{array}$ & $\begin{array}{l}\text { Gastrooesophageal } \\
\text { reflux disease (GERD) }\end{array}$ & $\begin{array}{l}\text { Chronic Cough (smoking, } \\
\text { post-infection, unknown) }\end{array}$ & $\begin{array}{l}\text { Symptom complex (dyspnea, } \\
\text { chest tightness, hyperventilation, } \\
\text { somatisation) }\end{array}$ & All non-asthmatic subjects \\
\hline n (\% distribution) & $337(69.6)$ & $55(37.4)$ & $40(27.2)$ & $30(20.4)$ & $22(15.0)$ & $147(30.4)$ \\
\hline Gender male/female (\% distribution) & 129/208 (38.3/61.7) & $26 / 29(47.3 / 52.7)$ & $18 / 22(45.0 / 55.0)$ & $18 / 12(60.0 / 40.0)$ & 8/14 (36.4/63.6) & $70 / 77(47.6 / 52.4)$ \\
\hline Age in years (mean $\pm S D$ ) (age-range) & $41.3 \pm 18.9(9.1-87.1)$ & $47.0 \pm 17.0(10.6-80.5)$ & $55.0 \pm 15.3(26.3-83.1)$ & $55.2 \pm 17.3(15.9-82.8)$ & $40.4 \pm 18.4(13.9-72.9)$ & $49.9 \pm 17.5(10.6-82.8)$ \\
\hline \multicolumn{7}{|c|}{ Functional Characteristics of plethysmographic measurements assessed by $z$-scores $n$ (\% within group) } \\
\hline Normal LF & $280(83.1)$ & $42(76.4)$ & $31(77.5)$ & $26(86.7)$ & $19(86.4)$ & $118(80.3)$ \\
\hline Pulmonary hyperinflation (PHI) & $28(8.3)$ & $12(21.8)$ & $7(17.5)$ & $2(6.7)$ & $3(13.6)$ & $24(16.3)$ \\
\hline Bronchial obstruction $(\mathrm{O})$ & $26(7.7)$ & $1(1.8)$ & $2(5.0)$ & 0 & 0 & $3(2.0)$ \\
\hline $\mathrm{PHI}$ and $\mathrm{O}$ & $3(0.9)$ & 0 & 0 & $2(6.7)$ & 0 & $2(1.4)$ \\
\hline \multicolumn{7}{|c|}{ Functional Characteristics of spirometric measurements assessed by z-scores by plethysmography $n(\%)$} \\
\hline Normal F-V curve & $305(90.5)$ & $50(36.9)$ & $40(100)$ & $29(96.7)$ & $19(86.4)$ & $138(93.9)$ \\
\hline Flow limitation (FL) & $26(7.7)$ & $5(9.1)$ & 0 & $1(3.3)$ & $3(13.6)$ & $9(6.1)$ \\
\hline SAD & $1(0.3)$ & 0 & 0 & 0 & 0 & $0(0)$ \\
\hline FL \& SAD & $5(1.53)$ & 0 & 0 & 0 & 0 & 0 \\
\hline
\end{tabular}




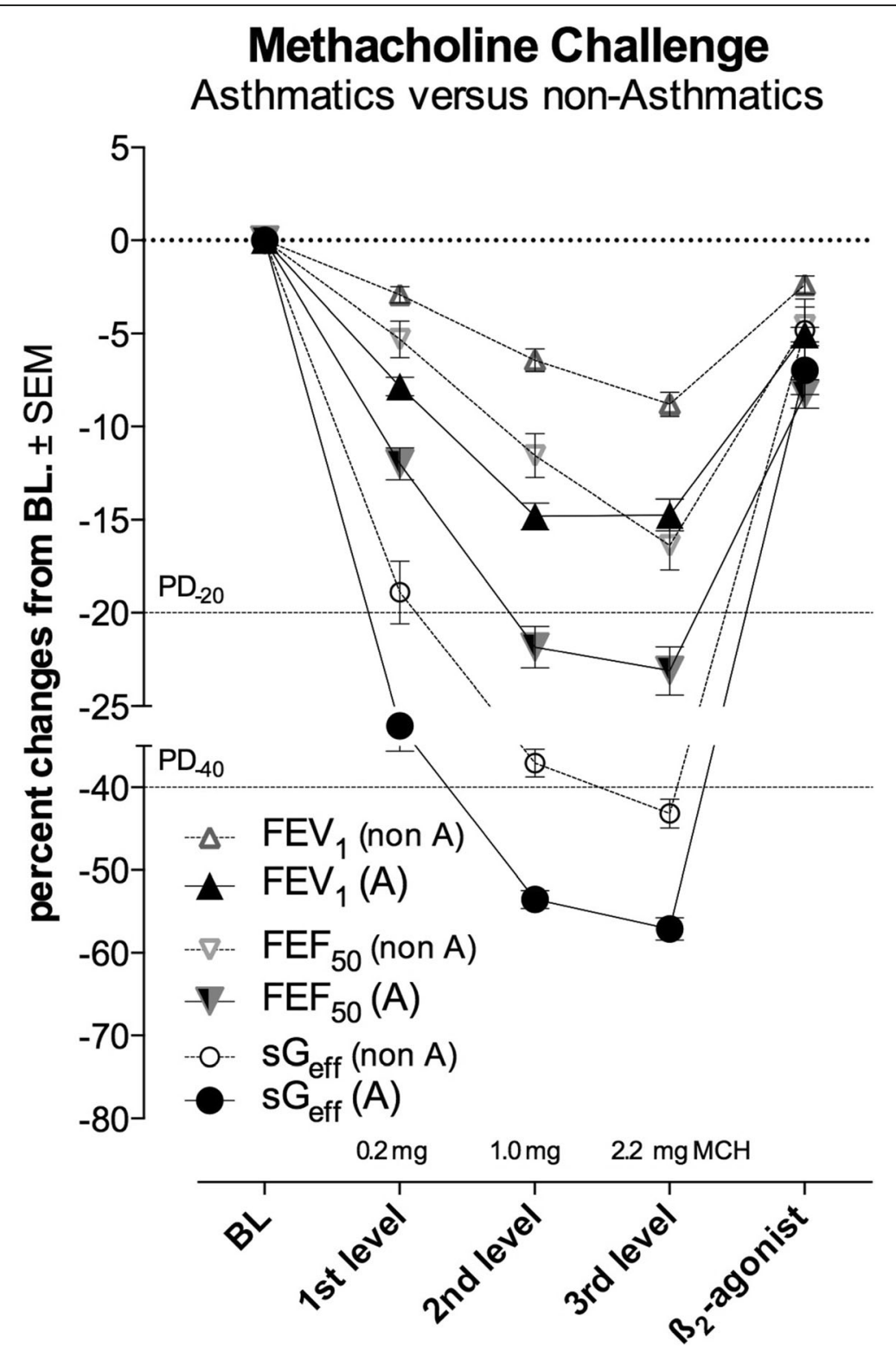

Fig. 2 Dose-response curves of methacholine at each consecutive provocation levels (PD): 0.2 mg; $\mathrm{PD}_{2}: 1.0 \mathrm{mg} ; \mathrm{PD}_{3}$ : 2.2 mg methacholine and reversibility to a $\beta_{2}$-agonist) referred for effective specific conductance $\left(\mathrm{sG}_{\mathrm{eff}}\right)$, forced expiratory volume in one second $\left(F E V_{1}\right)$ and forced expiratory flow at $50 \%$ vital capacity $\left(\mathrm{FEF}_{50}\right)$ in relation to the PD-level $-20 \%\left(\mathrm{PD}_{-20}\right)$ for $\mathrm{FEV}_{1}$ and $\mathrm{FEF}_{50}$, PD-level $-40 \%$ (PD-40) for sGeff resp., regarding asthmatic patients ( $\mathrm{A}=$ in comparison with non-asthmatic subjects (non- $\mathrm{A}$ )

evaluates changes of airway mechanics concomitantly with changes of EELV during MCT.

\section{Receiver operating characteristics}

Receiver operating curves (ROC) describing the relationship between sensitivity and specificity of percent changes during MCT of the 3 lung function parameters are given in Fig. 4. The area under the curve (AUC) for absolute change of $\mathrm{sG}_{\text {eff }}$ yielded the greatest value for $\mathrm{PD}_{-40} \mathrm{SG}_{\text {eff }}(.859 ; 95 \% \mathrm{CI}: .857-.897)$ compared to $\mathrm{PD}_{-45} \mathrm{SG}_{\text {eff }}$ and $\mathrm{PD}_{-50} \mathrm{SG}_{\text {eff }}$ on one hand, and compared to $\mathrm{PD}_{-20} \mathrm{FEV}_{1}(.749 ; 95 \% \mathrm{CI}$. $705-.793)$ and $\mathrm{PD}_{-20} \mathrm{FEF}_{50}(.729 ;) 5 \% \mathrm{CI}$. .680-.778) on the other hand. Considerable differences are also found regarding the Youden J-index and the likelihood ratios, both estimates of diagnostic test performance.

\section{Discussion}

\section{Key findings}

The principal goal of our study was to demonstrate that the performance of MCTs using the plethysmographic technique in addition to the spirometric approach offers 
Table 2 Measures of $\mathrm{MCH}$-challenge procedures computed for response characteristics of $\mathrm{sG}_{\mathrm{eff}}, \mathrm{FEV}_{1}$ and $\mathrm{FEF}_{50}$

\begin{tabular}{|c|c|c|c|c|c|}
\hline & $\mathrm{PD}_{-40} \mathrm{SG} \mathrm{eff}_{\mathrm{ff}}$ & $\mathrm{PD}_{-45} \mathrm{SG}_{\mathrm{eff}}$ & $\mathrm{PD}_{-50} \mathrm{SG}_{\mathrm{eff}}$ & $\mathrm{PD}_{-20} \mathrm{FEV}_{1}$ & $\mathrm{PD}_{-20} \mathrm{FEF}_{50}$ \\
\hline $\mathrm{N}$ & 484 & 484 & 484 & 484 & 484 \\
\hline PD-level not reached (\%) & $0(0)$ & $6(1.2)$ & $16(3.3)$ & $44(9.1)$ & $31(6.4)$ \\
\hline \multicolumn{6}{|c|}{ Diagnostic accuracy differentiating AHR from non-AHR in all patients but excluding patients not having reached PD-level } \\
\hline n (\%) & $484(100)$ & $478(98.8)$ & $468(96.7)$ & $440(90.9)$ & $453(93.6)$ \\
\hline Prevalence & $69.6 \%$ & $69.6 \%$ & $69.6 \%$ & $69.6 \%$ & $69.6 \%$ \\
\hline Sensitivity & $93.2 \%$ & $89.3 \%$ & $82.8 \%$ & $54.9 \%$ & $71.5 \%$ \\
\hline Specificity & $35.4 \%$ & $44.2 \%$ & $52.4 \%$ & $85.0 \%$ & $55.1 \%$ \\
\hline PPV & $76.8 \%$ & $78.6 \%$ & $79.9 \%$ & $89.4 \%$ & $78.5 \%$ \\
\hline NPV & $69.3 \%$ & $64.4 \%$ & $57.0 \%$ & $45.1 \%$ & $45.8 \%$ \\
\hline Diag. Odds Ratio (DOR) [33] & 7.473 & 6.628 & 5.291 & 6.915 & 3.081 \\
\hline $95 \% \mathrm{Cl}$ of $\mathrm{DOR}$ & $4.347-12.847$ & $4.123-10.655$ & $3.443-8.133$ & $4.189-11.417$ & $2.061-4.605$ \\
\hline pos. LR & 1.443 & 1.600 & 1.739 & 3.660 & 1.592 \\
\hline neg. LR & 0.192 & 0.242 & 0.328 & 0.531 & 0.517 \\
\hline Diagnostic effectiveness & 0.756 & 0.756 & 0.736 & 0.641 & 0.665 \\
\hline \multicolumn{6}{|c|}{ Cumulative percent-response in all patients (asthmatics and non-asthmatic subjects) at each provocation level n/n (\%) } \\
\hline $1^{\text {st }}$ PD level (\%) & $161 / 484(42.4)$ & $126 / 484(26.0)$ & 94/484 (19.4) & $94 / 484(9.7)$ & 99/484 (20.5) \\
\hline $2^{\text {nd }}$ PD level (\%) & $362 / 484(74.8)$ & $326 / 484(67.4)$ & $296 / 484(61.2)$ & $217 / 484(44.8)$ & 280/484 (57.9) \\
\hline $3^{\text {rd }}$ PD level (\%) & $415 / 484(85.7)$ & $395 / 484(81.6)$ & $376 / 484(77.7)$ & 270/484 (55.8) & $344 / 484(71.1)$ \\
\hline No AHR detected & $104 / 484(21.5)$ & $132 / 484(27.3)$ & $164 / 484$ (33.9) & $302 / 484(62.4)$ & 206/484 (42.6) \\
\hline
\end{tabular}

$P D$ provocation dose, $P P V$ positive predictive value, NPV negative predictive value, $L R$ likelihood ratio, DOR diagnostic odds ratio [33]

some fundamental benefits, such as independence from deep inspiration, and hence, modulation of the airway calibre [10, 31-36], avoidance of forced expiratory manoeuvres, and hence the subject's cooperation and coordination, which is known to change the airway responsiveness during the test procedure [34, 37, 38]. There are two important denouements, which are achieved, if the spirometric assessment of AHR is combined with wholebody plethysmography. First, MCTs based on a plethysmographic approach offers improved diagnostic accuracy. Second, the broncho-provocating process by $\mathrm{MCH}$ in relation to the development of pulmonary hyperinflation and/or the phenomenon of dysanapsis, the ratio $\mathrm{FEF}_{25-75} / \mathrm{FVC}$ thought to be a surrogate measure of airway size relative to lung size significantly associated with AHR [44]. The present study positively confirms the findings of Nensa et al. [10] reinforcing $s R_{\text {eff, }}$ and its reciprocal value $s G_{\text {eff }}$ respectively, as the most useful target parameters in the detection of AHR. Due to our observations of much higher percentresponse to $\mathrm{MCH}$ by $\mathrm{PD}_{-40} \mathrm{SG}_{\text {eff }}$ than by $\mathrm{PD}_{-20} \mathrm{FEV}_{1}$, we suggest, that some false negative $\mathrm{PD}_{-20} \mathrm{FEV}_{1}$ tests resulted in an underestimation of the severity of AHR, and hence potentially missed the diagnosis of asthma. In the following discussion we would like to focus on some important aspects of MCT performed by whole-body plethysmography, if combined with the spirometric assessment. Furthermore, we evaluate the physiological aspects of the so-called dysanapsis [13, 14], which was found to be an important determinant of AHR to $\mathrm{MCH}$, and hence airway narrowing during $\mathrm{MCT}$ by different author-groups [15-17, 45].

\section{Diagnostic accuracy}

There is an increasing interest to define proximity of measurement results comparing different test procedures. Recently Porpodis et al. [46] compared the diagnostic validity of $\mathrm{MCH}$ with mannitol. Based on their spirometric $\mathrm{PD}_{-20} \mathrm{FEV}_{1}$-results they found that both challenge tests were equivalent in diagnosing asthma. In the present study, however, we first look at the accuracy of different target lung function parameters, which could be discriminative between "asthma" and "non-asthma".

The most remarkable finding of the present study is that the $\mathrm{sG}_{\text {eff }}$ with a provocation level of $\mathrm{PD}_{-40}$ presented the highest diagnostic accuracy (sensitivity, specificity likelihood ratio, diagnostic odds ratios, ROC curves) for the diagnosis of asthma. In comparison with $\mathrm{PD}_{-20} \mathrm{FEV}_{1}$ and $\mathrm{PD}_{-20} \mathrm{FEF}_{50}$ the response-pattern to $\mathrm{MCH}$ evaluated by $\mathrm{PD}_{-40} \mathrm{SG}_{\text {eff }}$ was consistently different. Identical agreement regarding severity of AHR was only found in 159 (32.9\%) cases (44 severe AHR, 50 moderate AHR, 19 low AHR, 46 no AHR). In comparison to $\mathrm{PD}_{-40} \mathrm{SG}_{\text {eff, }}$ AHR-responses of $\mathrm{PD}_{-20} \mathrm{FEV}_{1}$ were observed in 83 (24.9\%) cases only one PD-level later, in another 73 (21.9\%) cases only two PD-levels later, and in $20(6.0 \%)$ cases even only three PD-levels later. 
Table 3 Test-duration and provocation-doses of methacholine $(\mathrm{mg})$ needed to achieve the different provocation-dose levels

\begin{tabular}{|c|c|c|c|c|c|}
\hline \multicolumn{6}{|c|}{ Comparison of average test-duration until different PD-levels reached } \\
\hline & Number & Mean & SD & Lower $95 \% C L$ & Upper 95\%CL \\
\hline $\mathrm{PD}_{40} s \mathrm{G}_{\mathrm{eff}}$ & 484 & $14: 45$ & 05:54 & 14:15 & $15: 14$ \\
\hline $\mathrm{PD}_{20} \mathrm{FEV}_{1}$ & 484 & 17:46 & 05:16 & 17:18 & 18:14 \\
\hline $\mathrm{PD}_{20} \mathrm{FEF}_{50}$ & 484 & $16: 17$ & 05.36 & $15: 47$ & $16: 47$ \\
\hline \multicolumn{6}{|c|}{ Test-duration: $\mathrm{sG}_{\mathrm{eff}}<\mathrm{FEV}_{1} ; \mathrm{sG}_{\mathrm{eff}}<\mathrm{FEF}_{50} ; \mathrm{FEF}_{50}<\mathrm{FEV}_{1}(\mathrm{p}<0.001)$} \\
\hline \multicolumn{6}{|c|}{ Provocation-doses of methacholine $(\mathrm{mg})$ needed to reach the different PD levels } \\
\hline \multicolumn{6}{|c|}{$\mathrm{PD}_{40} s \mathrm{G}_{\text {eff }}$} \\
\hline AHR & 409 & .495 & .491 & .447 & .543 \\
\hline No AHR & 75 & 2.185 & .059 & 2.17 & 2.197 \\
\hline \multicolumn{6}{|c|}{$\mathrm{PD}_{20} \mathrm{FEV}_{1}$} \\
\hline$A H R$ & 176 & .739 & .615 & .647 & .830 \\
\hline No AHR & 243 & 2.189 & .044 & 2.183 & 2.194 \\
\hline PD-level not reached & 65 & .873 & .450 & .761 & .985 \\
\hline \multicolumn{6}{|c|}{$\mathrm{PD}_{20} \mathrm{FEF}_{50}$} \\
\hline$A H R$ & 307 & .625 & .588 & .559 & .691 \\
\hline No AHR & 146 & 2.188 & .046 & 2.180 & 2.195 \\
\hline PD-level not reached & 31 & .936 & .496 & .754 & 1.117 \\
\hline \multicolumn{6}{|c|}{ Comparison between the 3 test procedures assessed by summary independent sample $t$-test } \\
\hline & & mean diff. & SE & t & Significance \\
\hline $\mathrm{PD}_{40} \mathrm{SG}_{\mathrm{eff}}$ versus $\mathrm{PD}_{20}$ & & .244 & .048 & 5.088 & $p<.000$ \\
\hline $\mathrm{PD}_{40} \mathrm{~s} \mathrm{G}_{\text {eff }}$ versus $\mathrm{PD}_{20}$ & & .130 & .040 & 3.223 & $p=.001$ \\
\hline $\mathrm{PD}_{20} \mathrm{FEV}_{1}$ versus $\mathrm{PD}_{20}$ & & .114 & .056 & 2.011 & $p=.045$ \\
\hline
\end{tabular}

Furthermore, in contrast to $\mathrm{PD}_{-40} \mathrm{~s} \mathrm{G}_{\text {eff }}$, the level of $\mathrm{PD}$ ${ }_{-20} \mathrm{FEV}_{1}$ was not reached in 65 cases (13.5\%). It follows that in $67.1 \%$ of asthmatic patients, a disagreement regarding $\mathrm{MCH}$-response between $\mathrm{PD}_{-40} \mathrm{SG}$ eff and $\mathrm{PD}_{-20} \mathrm{FEV}_{1}$ was found. Since the diagnosis of asthma was primarily based on the results of AHR evaluated by $\mathrm{PD}_{-20} \mathrm{FEV}_{1}$ the question remains open whether or not some asthmatics are hidden in the collective of patients diagnosed as chronic cough disease. This question, however, can only be answered by a properly planned prospective study.

\section{Deep inspiration during MCT}

It has well been recognised that deep inspirations play a major role in modulating airway calibre and airway responsiveness. In healthy subjects, deep inspirations reduce the level of pharmacologically induced airway obstruction by bronchodilation [45], whereas prohibition of taking deep breaths enhances the reaction to a broncho-constrictor agent [33]. Moreover, it has been recognised that inhalations to total lung capacity are broncho-protective, particularly in subjects with borderline AHR and non-asthmatics [34]. However, it has also been shown, that in asthmatics with mild AHR, deep inhalations do not produce a significantly lower response to $\mathrm{MCH}[37,47]$ than tidal breathing [40].
Site of action and interrelationship with dysanapsis

For many years it has been recognised that one factor determining the presence of AHR to broncho-provocative agents such as $\mathrm{MCH}$ is airway size. It varies from one individual to another, and some of this variability cannot be explained by differences in lung size between individuals $[15,16]$. The term "dysanapsis" was initially proposed by Green et al. [13] to describe this disproportionate, but physiologically normal and gender-specific growth between airways and lung parenchyma. The wide variation in maximal expiratory flow rates between individuals with similar lung size was interpreted to mean that there is no consistent association between lung and airway size. Mead [14] determined the association between airway size and lung size in adult women and men. He found that healthy adult men have airways that are larger in diameter than the airways of women. Moreover, it was concluded that women and boys have airways that are smaller relative to lung size compared to men, and therefore, the apparent gender-based differences occur late in the growth period. These findings were confirmed by Shell et al. [48], demonstrating evidence for gender-specific dysanapsis as shown by computer tomography (CT) imaging. There are significant male-female differences in the luminal areas of the larger and central airways, which are not accounted for by differences in lung size. 


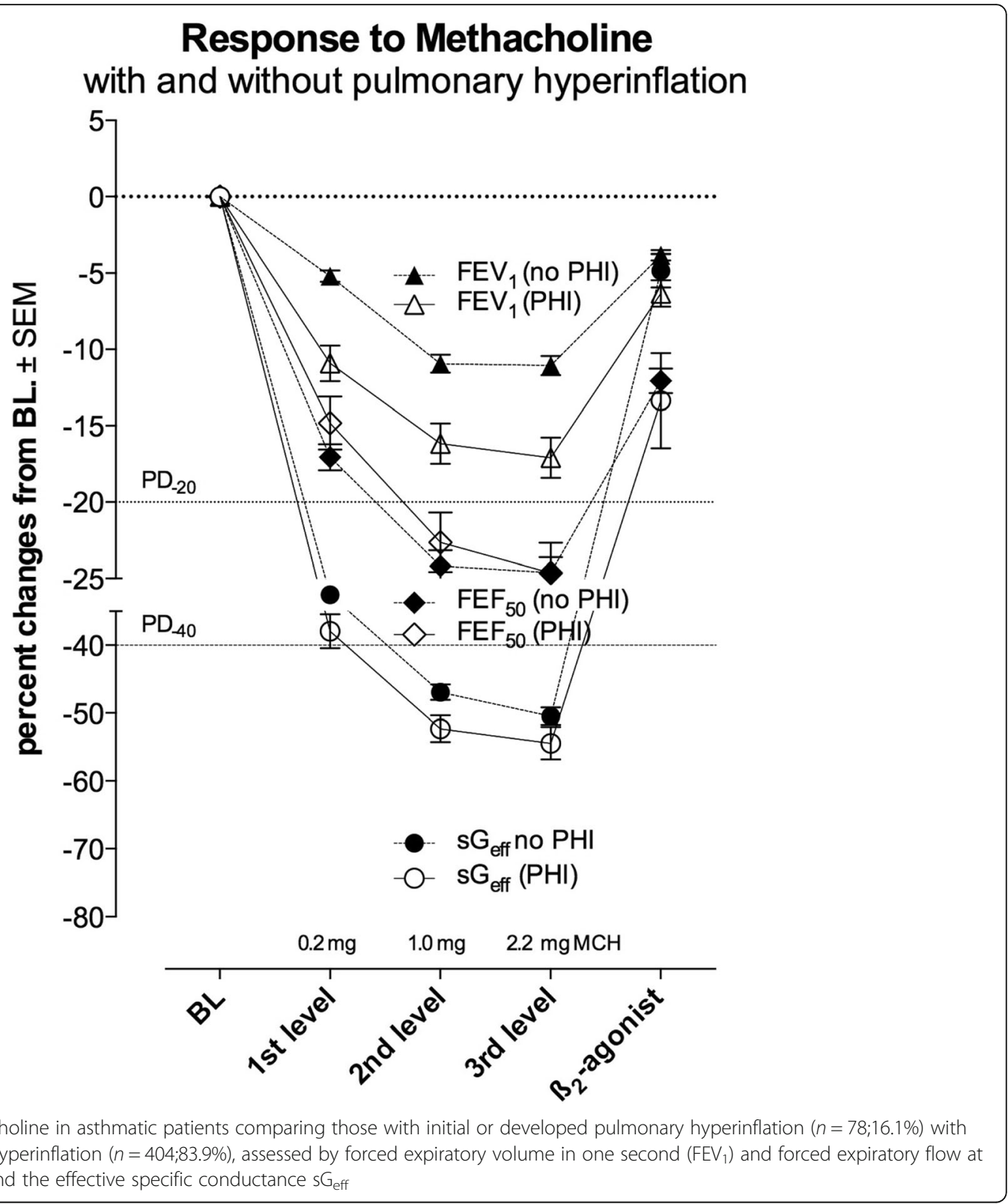

Forced expiratory flow between 25 and $75 \%$ of vital capacity $\left(\mathrm{FEF}_{25-75}\right)$ is considered as the most effortindependent part of the flow volume curve. This fraction is very sensitive regarding flow-limitation in peripheral airways, when chronic airflow obstruction is present [13]. Since direct measures of airway mechanics and lung size are often not available concomitantly, and $\mathrm{FEF}_{25-75}$ and forced vital capacity (FVC) are measured routinely during forced breathing manoeuvres, the ratio between $\mathrm{FEF}_{25-75}$ and FVC has been taken as a surrogate measure of dysanapsis $[7,13,14,17,44]$. Parker et al. [17] showed that when subjects were classified into four groups according to their $\mathrm{FEF}_{25-75} / \mathrm{FVC}$ ratio, subjects with lowest ratio also had the lowest $\mathrm{PD}_{-20} \mathrm{FEV}_{1}$, supporting the notion that subjects who are more sensitive to $\mathrm{MCH}$ have smaller airway calibres in relation to their lung size. They concluded that baseline $\mathrm{FEF}_{25-75} /$ FVC ratio could be a determinant of AHR to $\mathrm{MCH}$. Moreover, Mirsadraee et al. [7] showed that the diagnostic accuracy of $\mathrm{PC}_{-20} \mathrm{FEF}_{25-75} / \mathrm{FVC}$ and $\mathrm{PD}_{-20} \mathrm{FEF}_{50}$ were similar to $\mathrm{PD}_{-35} \mathrm{SG}$ aw and superior to $\mathrm{PD}_{-20} \mathrm{FEV}_{1}$.

The analysis in a subgroup of our asthmatic patients $(n=363)$ regarding dysanapsis expressing the $\mathrm{FEF}_{25-75} /$ FVC ratio as age- and gender-specific quartiles showed significant association to the severity of AHR assessed by $\mathrm{PD}_{-40} \mathrm{SG}_{\text {eff, }} \mathrm{PD}_{-20} \mathrm{FEV}_{1}$, and $\mathrm{PD}_{-20} \mathrm{FEF}_{50}$. However, within these quartiles of dysanapsis the response-pattern of the 3 lung function parameters were completely different. The differences between severe and medium AHR can be much better presented by $\mathrm{PD}_{-40} \mathrm{SG}_{\text {eff }}$ 


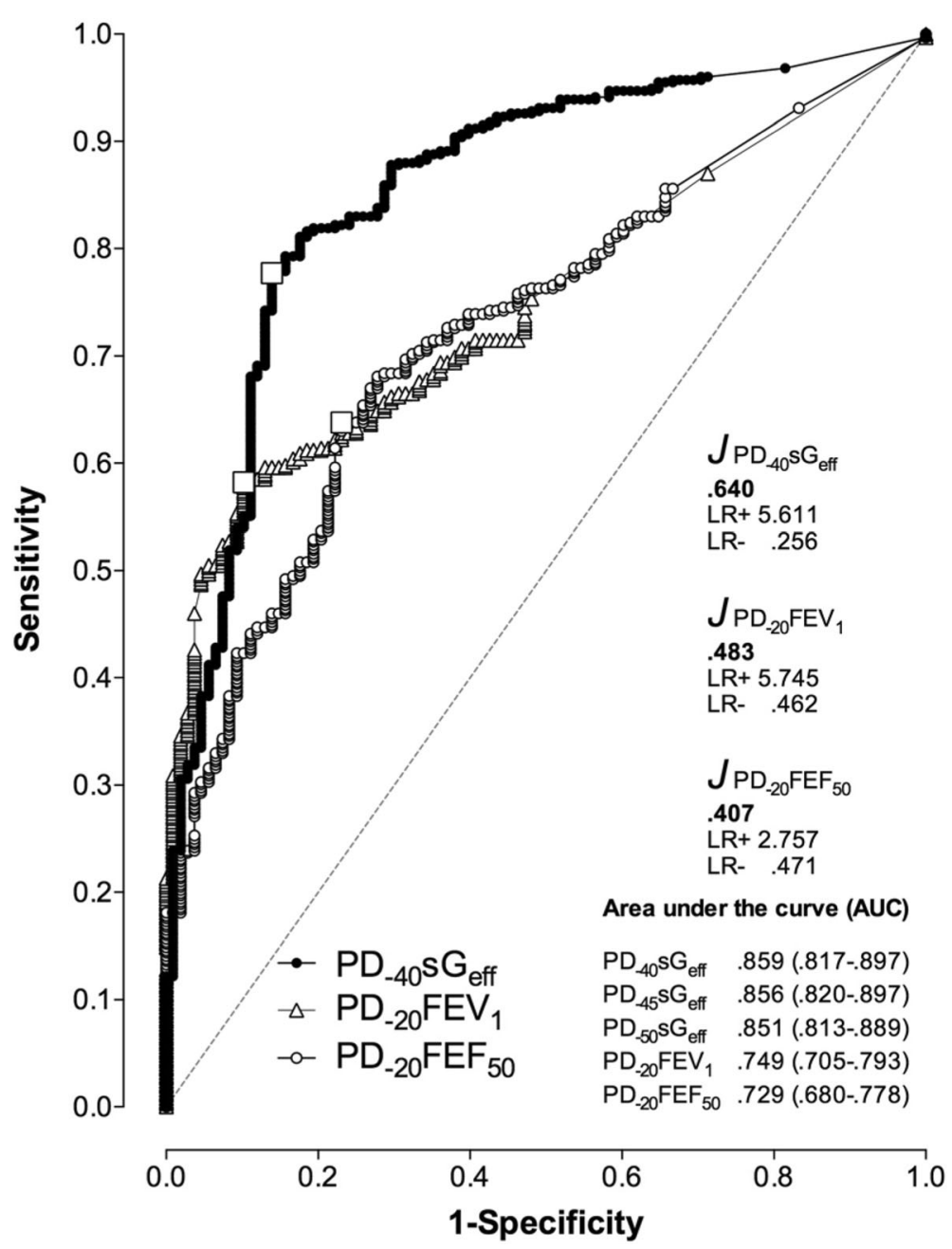

Fig. 4 Receiver operating curves (ROC) describing the relationship between sensitivity and specificity of percent changes obtained at the corresponding provocation dose levels, $\mathrm{PD}_{-40} \mathrm{SG}$ Geff for a $40 \%$ fall in effective specific conductance, $\mathrm{PD}_{-20} \mathrm{FEV}_{1}$ for a $20 \%$ fall in forced expiratory volume in one second, and $\mathrm{PD}_{-20} \mathrm{FEF}_{50}$ for a $20 \%$ fall in forced expiratory flow at 50\% vital capacity during methacholine challenge represented by methacholine

(36.7\%, 46.7\%, resp.) than by $\mathrm{PD}_{-20} \mathrm{FEV}_{1}(8.2 \% 23.3 \%$, resp.), or by $\mathrm{PD}_{-20} \mathrm{FEF}_{50}$ (23.2\%, 34.9\%, resp.), if related to the phenomenon of "airway narrowing" by $\mathrm{FEF}_{25-75} /$ FVC ratios $<25 \%$ ile, 25 to $50 \%$ ile. These associations existed for both male and female asthmatics, indicating that as opposed to Gaw and sGaw, AHR assessed by $s G_{\text {eff }}$ represents a much wider range of central and peripheral airways within the bronchial tree. In line with Parker et al. [17] we therefore conclude that AHR assessed by $\mathrm{PD}_{-40} \mathrm{SG}_{\text {eff }}$ is in strong association with dysanapsis, and may well provide a new conceptual approach, and hence better understanding of mechanisms that predispose an individual to asthma. Within the group of non-asthmatic subjects $(n=148) 14$ (9.5\%) (8 males, 6 females) presented with a $\mathrm{PD}_{-40} \mathrm{SG}$ eff to be labelled as "severe", within the subgroup of dysanapsis with a ratio of $\mathrm{FEF}_{25-75} / \mathrm{FVC}<25 \%$ ile, and the question remains open whether in these patients the diagnosis "asthma" was missed, because the diagnosis "asthma" was only expressed when $\mathrm{PD}_{-20} \mathrm{FEV}_{1}$ demonstrated AHR.

\section{Limitations of method}

The present study has some limitations. Firstly, because this was a retrospective study, there is a potential risk that some asthmatic patients might have been under-diagnosed. As standard for the diagnosis "asthma" $\mathrm{PD}_{-20} \mathrm{FEV}_{1}$ was taken and it could well be that a certain number of patients with cough-related diseases should be attributed to the groups of "asthmatics", if in fact $\mathrm{PD}_{-40} \mathrm{SG}_{\text {eff }}$ indicated a moderate or high AHR, and the subject presented with a low $\mathrm{FEF}_{25-75} /$ FVC ratio. Secondly, the database from which the evaluation was performed offered only a small number of really healthy subjects. It is not totally excluded that some "potential false positive" responses in the non-asthmatic group might have been more prevalent compared to healthy controls, and the differences between the asthmatics and false positive 
responders might be smaller than with healthy subjects. Thirdly, usually a retrospective study looks backwards and examines exposures to suspected risks or protection factors in relation to an outcome that is established at the start of the study. In our case-control study, however, we evaluated individual lung functions within 2 diagnostic groups, and for each parameter the chance to obtain a comprehensive result regarding AHR was the same. Great care was taken to avoid biases for one or the other parameter and confounding factors such as the development of pulmonary hyperinflation or dysanapsis were carefully addressed.

\section{Conclusion}

Important findings in regard to the performance of MCT as a hallmark in the diagnosis of bronchial asthma could be discovered, if the spirometric approach is combined with the assessment by whole-body plethysmography. Where diagnostic accuracy is required, there are striking differences regarding the choice of target parameters. Although the spirometric assessment based on changes in $\mathrm{FEV}_{1}$ is regarded as the gold standard for evaluation of $\mathrm{MCT}$, this study shows some important physiological inadequacies, to be considered as prerequisites, which could well be important for diagnosing "asthma". Deep inspiration in the set-up of test-sequences should be carefully monitored, as it is inevitably linked to forced breathing manoeuvres. Using the APS technology within the Jaeger MasterLab plethysmograph, MCTs are by default based on plethysmographic tidal breathing analysis, applying breathing loops with an implementation of real-time multi-level integral computation of all data points throughout the whole breathing cycle. In this light the study demonstrates that the plethysmographic $\mathrm{sG}_{\text {eff }}$ features a highly sensitive and reproducible target parameter for the assessment of AHR by MCTs. Furthermore, the combined assessment of AHR by spirometry and whole-body plethysmography offers the possibility to include changes of EELV at $\mathrm{FRC}_{\text {pleth }}$ (and hence pulmonary hyperinflation), as well as the phenomenon of dysanapsis to be included into the differentiation between "asthmatic" and "non-asthmatics".

\section{Additional files}

Additional file 1: Paradigm shift in the assessment of airway mechanics. (DOCX $880 \mathrm{~kb}$ )

Additional file 2: The Aerosol Provocation System (APS). (DOCX $545 \mathrm{~kb}$ )

Additional file 3: Assessment of airway hyperreactivity (AHR) in practical terms. (DOCX $259 \mathrm{~kb}$ )

Additional file 4: Statistical approach. (DOCX $128 \mathrm{~kb}$ )

\section{Abbreviations}

AHR: Airway hyperreactivity; APS: Aerosol provocation system; ATS: American thoracic society; AUC: Area und the curve; BL: Baseline; CD: Cumulative dose; DOR: Diagnostic odds ratio; EELV: End-expiratory lung volume; ERS: European respiratory society; $\mathrm{FEF}_{25-75}$ : Forced expiratory flow between 25 and $75 \%$ vital capacity; $\mathrm{FEF}_{50}$ : Forced expiratory flow at $50 \%$ of vital capacity; $F E V_{1}$ : Forced expiratory volume in $1 \mathrm{~s} ; F C_{\text {pleth: }}$ : Plethysmographic functional residual capacity; FVC: Forced vital capacity; J: Youden's index; LR-: Negative likelihood ratio; LR+: Positive likelihood ratio; MCH: Methacholine; MCT: Methacholine challenge test; NPV: Negative predicting value; $\mathrm{P}_{\text {amb }}$ : Barometric pressure; PD: Provocation doses; $\mathrm{PD}_{-20} \mathrm{FEF}_{25-75}$ : Provocation dose at which the forced expiratory flow between 25 to $75 \%$ of forced vital capacity decreases at least 20\% from baseline; $\mathrm{PD}_{-20} \mathrm{FEV}_{1}$ : Provocation dose at which the forced expiratory volume in $1 \mathrm{~s}$ decreases at least 20\% from baseline; $\mathrm{PD}_{-40} \mathrm{~S} \mathrm{G}_{\text {eff: }}$ Provocation dose at at which the effective specific airway conductance decreases at least $40 \%$ from baseline; $P D_{-45} 5 G_{\text {eff }}$ Provocation dose at which the effective specific airway conductance decreases at least $45 \%$ from baseline; $\mathrm{PD}_{-50} \mathrm{SG}_{\text {eff }}$. Provocation dose at which the effective specific airway conductance decreases at least $50 \%$ from baseline; $\mathrm{P}_{\text {H2O }}$ : Saturated vapour water pressure; PPV: Positive predicting value; $R_{a w:}$ : Airway resistance (two-angle technique); ROC: Receiver operating curve; $\mathrm{SG}_{\text {aw: }}$ : Specific airway conductance (two-angle

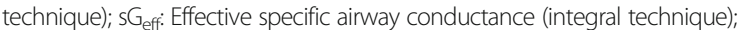
$s R_{a w}$ : Specific airway resistance (two-angle technique); $S R_{\text {eff. }}$ Effective specific airway resistance (integral technique); sWOB: Effective resistive work of breathing; $V^{\prime}$ : Flow; $\Delta V_{\text {box }}$ : Volume displacement of the plethysmographic box; $V_{T}$ : Tidal volume

\section{Acknowledgements}

We would like to thank Professor Sabina Gallati, PhD, Head of the Division of Human Genetics, University of Berne for the critical reviews of the manuscripts and Mrs. Zoe Clerc, Laboratory Technician, Division of Human Genetics, University of Berne for reviewing the English style of the manuscript.

Funding

For this study no funding was made.

Availability of data and materials

The datasets supporting the conclusions of this article are included within the article and its additional files.

\section{Authors' contributions}

RK $^{1}$ designed, coordinated and conceived the study. $\mathrm{H}$-JS took part in the interpretation of data and revising. TS, MF performed the clinical assessment of all patients and participated in the data collection, interpretation of data and revising. GG performed the lung function tests and participated in the data collection. $\mathrm{RK}^{2}$ designed and initiated the protocol of the methacholine challenge test. All authors supervised the study, read and approved the final manuscript.

\section{Competing interests}

The authors declare that they have no competing interests.

\section{Consent for publication}

This study evaluates retrospectively lung function data of a cases previously referred to the pulmonary function laboratory for baseline pulmonary function and $M C T$.

Ethics approval and consent to participate

The study was planned according to the Federal Law of Human Research, conceptualized according to the Swiss Ethics Committee on Research involving humans, and approved by the Governmental Ethics Committee of the State of Berne on Nov. 11, 2014 (Ref.-Nr KEK-BE: 325/2014. Head: Dr. Dorophy Pfiffner, PhD, PBox 56, CH3010 Berne, Switzerland). Master-files haven been stored and secured in the REDCap-system of the Clinical Trial Unit, Medical Faculty, University of Berne, Switzerland.

\section{Author details}

${ }^{1}$ Department of Clinical Research, University of Berne, Kirchenfeldstrasse 74, CH-3005 Berne, Switzerland. ${ }^{2}$ Medical Development, Research in Respiratory Diagnostics, Berlin, Germany. ${ }^{3}$ Division of Pulmonary Medicine, Clinic Barmelweid, CH-5017 Barmelweid, Switzerland.

Received: 16 August 2016 Accepted: 4 November 2016 Published online: 17 November 2016 


\section{References}

1. Sterk PJ, Fabbri LM, Quanjer PH, Cockcroft DW, O'Byrne PM, Anderson SD, Juniper EF, Malo JL. Airway responsiveness. Standardized challenge testing with pharmacological, physical and sensitizing stimuli in adults. Report working party standardization of lung function tests, european community for steel and coal. Official statement of the european respiratory society. Eur respir J Suppl. 1993;16:53-83.

2. Greenspon LW, Gracely E. A discriminant analysis applied to methacholine bronchoprovocation testing improves classification of patients as normal, asthma, or COPD. Chest. 1992;102:1419-25.

3. Anderson SD, Brannan J, Spring J, Spalding N, Rodwell LT, Chan K, Gonda I, Walsh A, Clark AR. A new method for bronchial-provocation testing in asthmatic subjects using a dry powder of mannitol. Am J Respir Crit Care Med. 1997;156:758-65.

4. Crapo RO, Casaburi R, Coates AL, Enright PL, Hankinson JL, Irvin CG, MacIntyre NR, McKay RT, Wanger JS, Anderson SD, Cockcroft DW, Fish JE, Sterk PJ. Guidelines for methacholine and exercise challenge testing-1999. Am J Respir Crit Care Med. 2000;161:309-29.

5. Parker AL, McCool FD. Pulmonary function characteristics in patients with different patterns of methacholine airway hyperresponsiveness. Chest. 2002;121:1818-23.

6. Garcia-Rio F, Mediano O, Ramirez M, Vinas A, Alonso A, Alvarez-Sala R, Pino JM. Usefulness of bronchial reactivity analysis in the diagnosis of bronchial asthma in patients with bronchial hyperresponsiveness. Respir Med. 2004;98:199-204.

7. Mirsadraee M, Forouzesh B, Roshandel E, Meshkat M, Boskabady MH. Accuracy of mid expiratory flow and dysanapsis parameters for evaluation of methacholine provocation test. Tanaffos. 2009;8:24-30.

8. Nensa F, Marek W, Marek E, Smith HJ, Kohlhaufl M. Assessment of airway hyperreactivity: comparison of forced spirometry and body plethysmography for methacholine challenge tests. Eur J Med Res. 2009;14 Suppl 4:170-6.

9. Sumino K, Sugar EA, Irvin CG, Kaminsky DA, Shade D, Wei CY, Holbrook JT, Wise RA, Castro M. Methacholine challenge test: diagnostic characteristics in asthmatic patients receiving controller medications. J Allergy Clin Immunol. 2012;130:69-75. e66.

10. Nensa F, Kotschy-Lang N, Smith HJ, Marek W, Merget R. Assessment of airway hyperresponsiveness: comparison of spirometry and body plethysmography. Adv Exp Med Biol. 2013;755:1-9.

11. Cockcroft DW, Davis BE. Mechanisms of airway hyperresponsiveness. J Allergy Clin Immunol. 2006;118:551-9. quiz 560-551.

12. Juniper EF, Frith PA, Hargreave FE. Airway responsiveness to histamine and methacholine: relationship to minimum treatment to control symptoms of asthma. Thorax. 1981;36:575-9.

13. Green M, Mead J, Turner JM. Variability of maximum expiratory flow-volume curves. J Appl Physiol. 1974;37:67-74.

14. Mead J. Dysanapsis in normal lungs assessed by the relationship between maximal flow, static recoil, and vital capacity. Am Rev Respir Dis. 1980;121:339-42

15. Martin TR, Castile RG, Fredberg JJ, Wohl ME, Mead J. Airway size is related to sex but not lung size in normal adults. J Appl Physiol (1985). 1987;63:2042-7.

16. Brooks LJ, Byard PJ, Helms RC, Fouke JM, Strohl KP. Relationship between lung volume and tracheal area as assessed by acoustic reflection. J Appl Physiol (1985). 1988;64:1050-4.

17. Parker AL, Abu-Hijleh M, McCool FD. Ratio between forced expiratory flow between $25 \%$ and $75 \%$ of vital capacity and FVC is a determinant of airway reactivity and sensitivity to methacholine. Chest. 2003;124:63-9.

18. Masoli M, Fabian D, Holt S, Beasley R, Global Initiative for Asthma. The global burden of asthma: executive summary of the GINA dissemination committee report. Allergy. 2004;59:469-78.

19. Pratter MR. Chronic upper airway cough syndrome secondary to rhinosinus diseases (previously referred to as postnasal drip syndrome): ACCP evidence-based clinical practice guidelines. Chest. 2006;129:63S-71S.

20. Chung KF, Pavord ID. Prevalence, pathogenesis, and causes of chronic cough. Lancet. 2008;371:1364-74.

21. Pellegrino R, Viegi G, Brusasco V, Crapo RO, Burgos F, Casaburi R, Coates A van der Grinten CP, Gustafsson P, Hankinson J, Jensen R, Johnson DC, Maclntyre N, McKay R, Miller MR, Navajas D, Pedersen OF, Wanger J. Interpretative strategies for lung function tests. Eur Respir J. 2005;26:948-68.

22. Miller MR, Hankinson J, Brusasco V, Burgos F, Casaburi R, Coates A, Crapo R, Enright $P$, van der Grinten CP, Gustafsson P, Jensen R, Johnson DC,
Maclntyre N, McKay R, Navajas D, Pedersen OF, Pellegrino R, Viegi G, Wanger J. Standardisation of spirometry. Eur Respir J. 2005;26:319-38.

23. Kraemer R, Blum A, Schibler A, Ammann RA, Gallati S. Ventilation inhomogeneities in relation to standard lung function in patients with cystic fibrosis. Am J Respir Crit Care Med. 2005;171:371-8.

24. Kraemer R, Delosea N, Ballinari P, Gallati S, Crameri R. Effect of allergic bronchopulmonary aspergillosis on lung function in children with cystic fibrosis. Am J Respir Crit Care Med. 2006;174:1211-20.

25. Kraemer R, Latzin P, Pramana I, Ballinari P, Gallati S, Frey U. Long-term gas exchange characteristics as markers of deterioration in patients with cystic fibrosis. Respir Res. 2009;10:106.

26. Goldman M, Smith HJ, Ulmer WT. Lung function testing: whole-body plethysmography. Eur Respir Soc Monogr. 2005;31:15-43.

27. Matthys $\mathrm{H}$, Orth U. Comparative measurements of airway resistance. Respiration. 1975:32:121-34.

28. Kraemer R, Baldwin DN, Ammann RA, Frey U, Gallati S. Progression of pulmonary hyperinflation and trapped gas associated with genetic and environmental factors in children with cystic fibrosis. Respir Res. 2006;7:138.

29. Stocks J, Quanjer PH. Reference values for residual volume, functional residual capacity and total lung capacity. ATS workshop on lung volume measurements. Official statement of the European respiratory society. Eur Respir J. 1995;8:492-506.

30. Brandli O, Schindler C, Kunzli N, Keller R, Perruchoud AP. Lung function in healthy never smoking adults: reference values and lower limits of normal of a Swiss population. Thorax. 1996;51:277-83.

31. Orehek J, Nicoli MM, Delpierre S, Beaupre A. Influence of the previous deep inspiration on the spirometric measurement of provoked bronchoconstriction in asthma. Am Rev Respir Dis. 1981;123:269-72.

32. Duggan CJ, Castle WD, Berend N. Effects of continuous positive airway pressure breathing on lung volume and distensibility. J Appl Physiol (1985). 1990;68:1121-6.

33. Skloot G, Permutt S, Togias A. Airway hyperresponsiveness in asthma: a problem of limited smooth muscle relaxation with inspiration. J Clin Invest. 1995:96:2393-403.

34. Kapsali T, Permutt S, Laube B, Scichilone N, Togias A. Potent bronchoprotective effect of deep inspiration and its absence in asthma. J Appl Physiol (1985). 2000;89:711-20

35. Salome CM, Thorpe CW, Diba C, Brown NJ, Berend N, King GG. Airway re-narrowing following deep inspiration in asthmatic and nonasthmatic subjects. Eur Respir J. 2003;22:62-8.

36. Slats AM, Janssen $K$, van Schadewijk A, van der Plas DT, Schot R, van den Aardweg JG, de Jongste JC, Hiemstra PS, Mauad T, Rabe KF, Sterk PJ. Bronchial inflammation and airway responses to deep inspiration in asthma and chronic obstructive pulmonary disease. Am J Respir Crit Care Med. 2007:176:121-8.

37. Allen ND, Davis BE, Hurst TS, Cockcroft DW. Difference between dosimeter and tidal breathing methacholine challenge: contributions of dose and deep inspiration bronchoprotection. Chest. 2005;128:4018-23.

38. Schulze J, Rosewich M, Riemer C, Dressler M, Rose MA, Zielen S. Methacholine challenge-comparison of an ATS protocol to a new rapid single concentration technique. Respir Med. 2009;103:1898-903.

39. Merget $R$, Jorres RA, Heinze E, Haufs MG, Taeger D, Bruning T. Development of a 1-concentration-4-step dosimeter protocol for methacholine testing. Respir Med. 2009;103:607-13.

40. Schulze J, Smith HJ, Fuchs J, Herrmann E, Dressler M, Rose MA, Zielen S. Methacholine challenge in young children as evaluated by spirometry and impulse oscillometry. Respir Med. 2012;106:627-34.

41. Kannan R, Guo P, Przekwas A. Particle transport in the human respiratory tract: formulation of a nodal inverse distance weighted Eulerian-Lagrangian transport and implementation of the Wind-Kessel algorithm for an oral delivery. Int J Numer Method Biomed Eng. 2016; 32(6). (ahead of print)

42. Irwig L, Bossuyt P, Glasziou P, Gatsonis C, Lijmer J. Designing studies to ensure that estimates of test accuracy are transferable. BMJ. 2002;324:669-71.

43. Glas AS, Lijmer JG, Prins MH, Bonsel GJ, Bossuyt PM. The diagnostic odds ratio: a single indicator of test performance. J Clin Epidemiol. 2003;56:1129-35.

44. Litonjua AA, Sparrow D, Weiss ST. The FEF25-75/FVC ratio is associated with methacholine airway responsiveness. The normative aging study. Am J Respir Crit Care Med. 1999:159:1574-9.

45. Scichilone N, Kapsali T, Permutt S, Togias A. Deep inspiration-induced bronchoprotection is stronger than bronchodilation. Am J Respir Crit Care Med. 2000;162:910-6. 
46. Porpodis K, Domvri K, Kontakiotis T, Fouka E, Kontakioti E, Zarogoulidis K, Papakosta D. Comparison of diagnostic validity of mannitol and methacholine challenges and relationship to clinical status and airway inflammation in steroid-naive asthmatic patients. J Asthma. 2016; (ahead of print).

47. Slats AM, Janssen K, de Jeu RC, van der Plas DT, Schot R, van den Aardweg JG, Sterk PJ. Enhanced airway dilation by positive-pressure inflation of the lungs compared with active deep inspiration in patients with asthma. J Appl Physiol (1985). 2008;105:1725-32.

48. Sheel AW, Guenette JA, Yuan R, Holy L, Mayo JR, McWilliams AM, Lam S, Coxson $\mathrm{HO}$. Evidence for dysanapsis using computed tomographic imaging of the airways in older ex-smokers. J Appl Physiol (1985). 2009;107:1622-8.

Submit your next manuscript to BioMed Central and we will help you at every step:

- We accept pre-submission inquiries

- Our selector tool helps you to find the most relevant journal

- We provide round the clock customer support

- Convenient online submission

- Thorough peer review

- Inclusion in PubMed and all major indexing services

- Maximum visibility for your research

Submit your manuscript at www.biomedcentral.com/submit 